\title{
An unusual mercury(II) di-isopropyldithiocarbamate coordination polymer
}

Alexander Angeloski ${ }^{a}$, Aditya Rawal ${ }^{b}$, Mohan Bhadbhade ${ }^{c}$ James M. Hook $^{b}$, Robert W. Schurko ${ }^{d}$ and Andrew M. McDonagh ${ }^{a *}$

${ }^{\text {a }}$ School of Mathematical and Physical Sciences, University of Technology Sydney, Ultimo, 2007, Australia.

${ }^{\mathrm{b}}$ NMR Facility, Mark Wainwright Analytical Centre, The University of New South Wales, Sydney, 2052, Australia.

${ }^{c}$ School of Chemistry, The University of New South Wales, Sydney, 2052, Australia.

${ }^{\mathrm{d}}$ Department of Chemistry and Biochemistry, University of Windsor, Windsor, Ontario, Canada N9B 3P4

\begin{abstract}
A new polymeric mercury(II) di-isopropyldithiocarbamate complex was synthesized by the reaction of sodium di-isopropyldithiocarbamate with excess $\mathrm{HgCl}_{2}$ in water. The precise structure of the new compound was determined by single crystal X-ray diffraction. A similar reaction, using a stoichiometric excess of the ligand, yielded the known monomeric bis(di(isopropyl)dithiocarbamato)mercury(II) complex. The complexes could not be distinguished from each other by their solution phase NMR spectra nor their FTIR spectra. Solid state NMR
\end{abstract}


spectroscopy $\left({ }^{199} \mathrm{Hg}\right.$ and $\left.{ }^{13} \mathrm{C}\right)$ provided unambiguous data and showed that the monomeric complex and polymeric complex do not interconvert in solution or during crystal growth. Thermogravimetric experiments revealed quite different thermal decomposition behaviour between the two compounds.

Keywords: dithiocarbamate, Hg NMR spectroscopy, mercury complexes 


\section{Introduction}

Metal dithiocarbamate complexes are renowned for their ease of synthesis, useful properties and co-ordination chemistries. ${ }^{1-16}$ The flexibility to readily engineer and alter the dithiocarbamate ligand allows a range of co-ordination complexes to be generated. Thus, metal dithiocarbamate complexes have been extensively studied in the area of crystal growth and design and as single

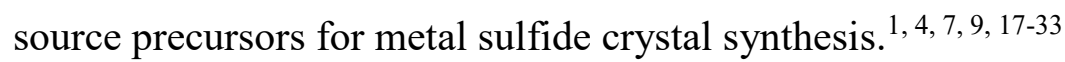

Of particular relevance to the current work, mercury (II) dithiocarbamate complexes produce a diverse range of molecular architectures and isomers; generating at least five distinct structural motifs in systems bearing two dithiocarbamate ligands. ${ }^{1}$ The reaction of $\mathrm{HgCl}_{2}$ with diethyldithiocarbamate has been reported to produce three unique crystals (two polymorphs and an isomer) during crystal growth. ${ }^{34-37}$ In this case, the isomer was identified as a polymeric dithiocarbamate complex consisting of bridging mercury chloride and dithiocarbamate moieties. Subsequently, the products of reactions of $\mathrm{HgCl}_{2}$ with diethyldithiocarbamate were found to be dependent on the ratio of ligand to metal. ${ }^{38}$

Reactions of $\mathrm{HgCl}_{2}$ with $\mathrm{S}$-donor ligands have a propensity to form co-ordination polymers by interaction with sulfur-containing species, ${ }^{39-41}$ although detailed studies of the formation of mercury co-ordination polymers are scarce, especially in the case of dithiocarbamates. ${ }^{36,42,43-47}$ Furthermore, the question of whether the mercury dithiocarbamate structures (i.e., monomer, dimer, or polymer) are formed during the initial reaction between metal and ligand or during crystal growth experiments remains unanswered. We therefore investigated the formation of mercury(II) di-isopropyldithiocarbamate complexes, which can exist in multiple structural forms. ${ }^{48-50} \mathrm{We}$ employed solid- and solution-state techniques to track the formation of monomeric, dimeric and polymeric mercury(II) di-isopropyldithiocarbamate complexes from the initial reaction between 
metal and ligand, to the isolation of individual crystals. Solid-state NMR $\left({ }^{13} \mathrm{C}\right.$ and $\left.{ }^{199} \mathrm{Hg}\right)$ spectroscopy and single crystal X-ray diffraction were definitive in demonstrating the structural differences.

\section{Results and Discussion}

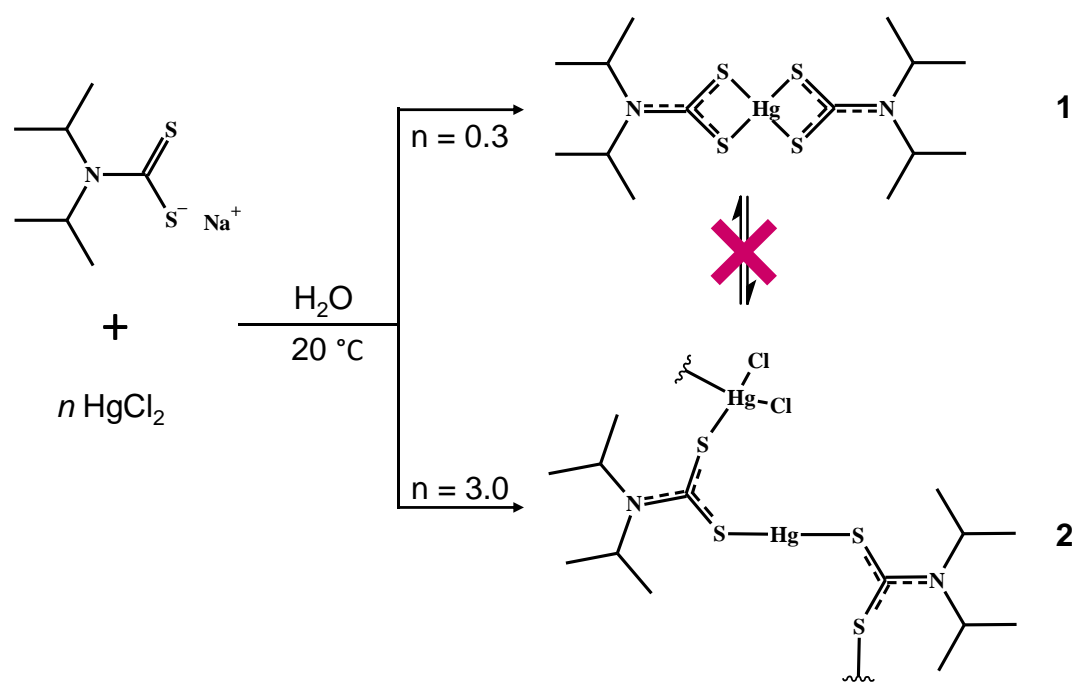

Scheme 1. Synthesis of 1 and 2.

Reaction of sodium di-isopropyldithiocarbamate ( $\mathrm{NaDIPDTC}$ ) with $\mathrm{HgCl}_{2}$ in a 3:1 molar ratio in water (Scheme 1) gave the known complex $\mathbf{1}^{48}$ (as determined by solid-state ${ }^{199} \mathrm{Hg} \mathrm{NMR}$ spectroscopy, see below) in $82 \%$ yield. In contrast, reaction of $\mathrm{NaDIPDTC}$ with $\mathrm{HgCl}_{2}$ in a $1: 3$ molar ratio produced a new complex, 2 , in 75\% yield. Reactions using a 2:1 molar ratio of NaDIPDTC to $\mathrm{HgCl}_{2}$ produced a mixture of $\mathbf{1}$ and 2.

The molecular structure of $\mathbf{1}$ was redetermined ${ }^{48}$ to obtain more precise data (significantly lower estimated standard deviations for bond lengths and angles) for comparison with solid-state NMR data (see below). The structure is shown in Figure 1. The co-ordination sphere of mercury is approximated as distorted tetrahedral, with two short (2.4428 (6) $\AA$, Hg1-S2) and two long (2.6523

(6) $\AA, \mathrm{Hg} 1-\mathrm{S} 1$ ) mercury-sulfur bonds. The $-\mathrm{C} 1 \mathrm{~S} 2 \mathrm{Hg}$ and $-\mathrm{C} 1 \mathrm{~N} 1 \mathrm{C} 2$ moieties are planar. There is one intramolecular $\mathrm{C}-\mathrm{H} \cdots \mathrm{S}$ hydrogen bond of $\sim 2.4 \AA$ between $\mathrm{S} 1$ and $\mathrm{H} 2$, creating an electronic 
asymmetry about the two isopropyl groups within each ligand, in agreement with previous reports. ${ }^{9-11}$ All ligand bond lengths are similar to those in other DIPDTC complexes. ${ }^{9-11,48,51-55}$

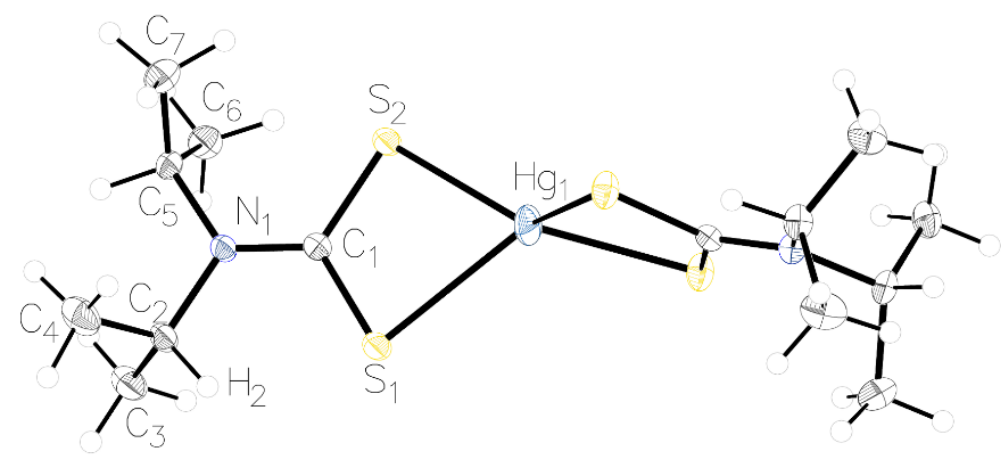

Figure 1: Structure of 1 showing the atom-labelling scheme and thermal displacement ellipsoids at $50 \%$ probability.

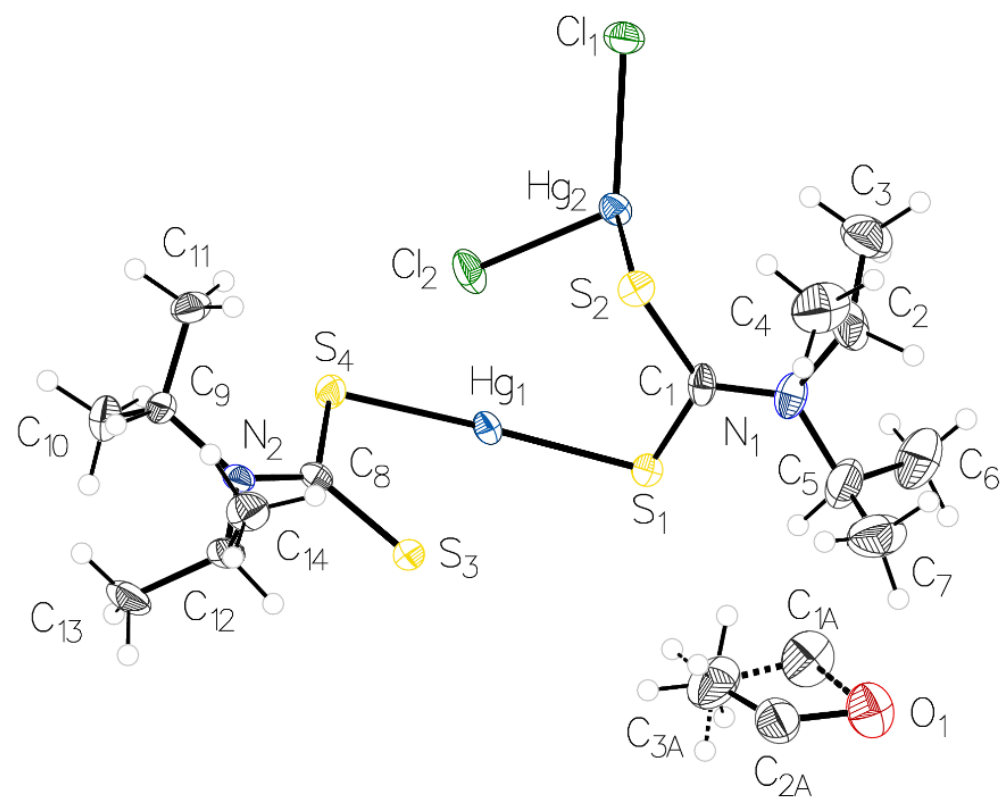

Figure 2: Structure of 2 (asymmetric unit) showing the atom labelling scheme and thermal displacement ellipsoids at $50 \%$ probability. 
The structure of polymeric $\mathbf{2}$ contains a bonding motif that is new for mercury dithiocarbamate complexes $^{1}$. The asymmetric unit (Figure 2) contains two monodentate, bridging dithiocarbamate ligands, two inequivalent mercury environments and a disordered diethyl ether molecule that occupies a special position on a crystallographic inversion centre. One mercury atom (Hg1) is coordinated by two monodentate dithiocarbamate ligands with equivalent $\mathrm{Hg}-\mathrm{S}$ bond lengths of 2.3686 (14) $\AA$ to produce an approximately linear environment with a S1-Hg1-S4 angle of 171.65 (5) ${ }^{\circ}$. The S-C-S bond angles are the same within each dithiocarbamate ligand. Both ligands are approximately planar with deviations of no greater than $0.06 \AA$ from their S-C-C-S least planes and torsion angles of $174.7(5)^{\circ}$ for $\mathrm{S} 1-\mathrm{C} 1-\mathrm{N} 1-\mathrm{C} 9$, and 178.6 (4) ${ }^{\circ}$ for S4-C8-N2-C12. The $-\mathrm{CS}_{2}$ moieties/planes are rotated relative to each other about the $\mathrm{S} 1-\mathrm{Hg} 1-\mathrm{S} 4$ bond by $96.6(3)^{\circ}$. A second mercury atom $(\mathrm{Hg} 2)$ is co-ordinated to two chlorine atoms $(\mathrm{Cl} 1$ and $\mathrm{Cl} 2)$, and the remaining sulfur atoms (S2 and S3) in a monodentate fashion. The co-ordination geometry about $\mathrm{Hg} 2$ is approximately tetrahedral, however all four bonds are inequivalent and range from 2.4526 (14) $\AA$ (between $\mathrm{Hg} 2-\mathrm{C} 11$ ) to 2.5691 (14) $\AA$ (between $\mathrm{Hg} 2-\mathrm{S} 3$ ). The $\mathrm{Hg} 2-\mathrm{S}$ bonds are similar in length to those found in $\mathbf{1}$ but the $\mathrm{Hg}-\mathrm{Cl}$ bonds are at least $0.2 \AA$ longer than those found in $\mathrm{HgCl}_{2}{ }^{39,56}$. 


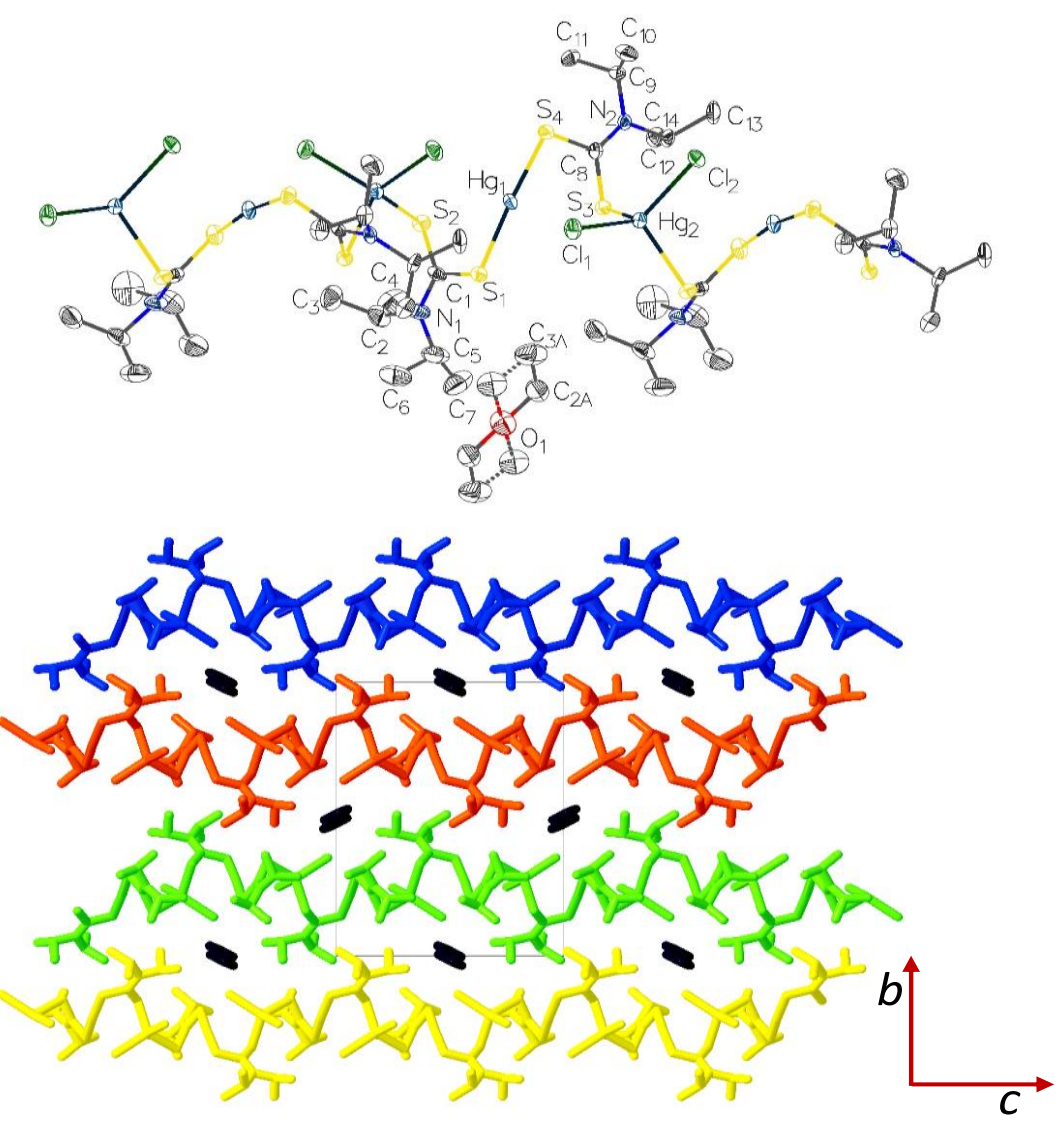

Figure 3: Top: Extended structure of $\mathbf{2}$ with thermal displacement ellipsoids at 50\% probability. Bottom: Crystal packing showing 1-D chains of 2 along the $c$ axis. Disordered ether molecules are shown in black and hydrogen atoms are omitted for clarity.

The structure contains chains of $\mathbf{2}$ that align parallel to the $c$ axis and arise from $\mathrm{Hg} 2-\mathrm{S}$ bonds between neighbouring asymmetric units (Figure 3). The individual parallel ribbons of polymeric $\mathrm{Hg}(\text { DIPDTC })_{2}$ maintain contact with each other through intermolecular $\mathrm{Hg}-\mathrm{Cl} \cdots \mathrm{H}-\mathrm{C}$ and C-S $\cdots \mathrm{H}-$ C interactions. There is an intramolecular C-S $\cdots \mathrm{H}-\mathrm{C}$ interaction between $\mathrm{S} 4$ and $\mathrm{H} 10 \mathrm{~A}$ of $\sim 2.7 \AA$. The disordered ether molecule resides in solvent-accessible voids within the structure and has no interactions with distances $<3 \AA$. Relevant crystal data for $\mathbf{1}$ and $\mathbf{2}$ can be found in the Supporting Information (Tables S1-S6). 


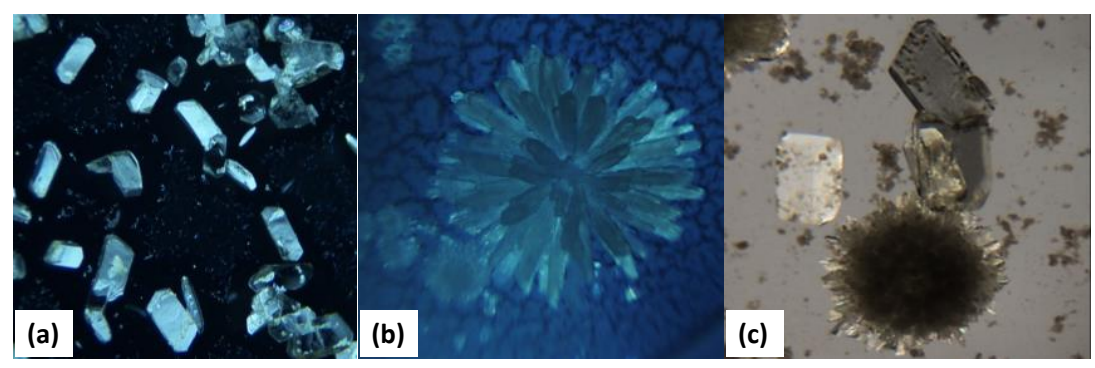

Figure 4: Photomicrographs showing the morphology of 1 (a), 2 (b) and crystallisation of 1 and 2 from a mixture of $\mathbf{1}$ and $\mathbf{2}$ (c).

Crystal growth experiments using solutions containing a mixture of $\mathbf{1}$ and $\mathbf{2}(\sim 1: 1$ ratio) yielded independent crystals of $\mathbf{1}$ and $\mathbf{2}$ (Figure 4), which could be physically separated on the basis of morphology. Interestingly, a previously described dimeric disappearing isomer of $\mathbf{1}^{50}$ was obtained during crystallisation experiments, and characterized by X-ray diffraction (see Supporting Information). Attempts to reproduce the material were unsuccessful after several months of trials.

Time-lapsed cross-polarized photomicroscopy (Video 1) during ether counter-diffusion into a chloroform solution of $\mathbf{1}$ was used to probe the crystallisation process. The onset of crystal growth occurs at $\mathrm{T}=80$ minutes, with active expansion of the crystal facets occurring until $\mathrm{T}=220$ minutes. Only a single morphology of crystals is produced, with no appearance of $\mathbf{2}$, indicating that there is no solution equilibrium between $\mathbf{1}$ and $\mathbf{2}$ during crystal growth. Further counter-diffusion of solvent occurs without any change in the morphology of crystallized 1, and total evaporation of the crystallisation solvent did not produce any further crystalline products (albeit at a cost of crystal destruction), Figure S1.

Solution-state ${ }^{1} \mathrm{H}$ and ${ }^{13} \mathrm{C}$ NMR spectra of $\mathbf{1}$ and $\mathbf{2}$ were indistinguishable. Spectra obtained using a mixture of $\mathbf{1}$ and $\mathbf{2}$ (determined using solid-state ${ }^{199} \mathrm{Hg}$ NMR spectroscopy) contained a single set of signals that remained indistinguishable even at lower temperatures $(238 \mathrm{~K})$. In addition, DOSY-NMR at room temperature (Figure S2) revealed a single set of signals with a single 
diffusion constant. However, the variable-temperature solution state NMR data (Figures S3-S5) revealed kinetic insights on the restricted rotation of the isopropyl groups (due to intramolecular $\mathrm{C}-\mathrm{H} \cdot \mathrm{S}$ interactions and steric effects) ${ }^{9,11}$ Examination of the variable-temperature experimental data yielded an energy barrier $\left(\Delta G^{\ddagger}\right)$ to free rotation at coalescence $(268 \mathrm{~K})$ of $59 \mathrm{~kJ} \mathrm{~mol}^{-1}$, which is in excellent agreement with our previously reported data for NaDIPDTC $\left(56 \mathrm{~kJ} \mathrm{~mol}^{-1}\right)^{11}$ and PbDIPDTC $\left(57 \mathrm{~kJ} \mathrm{~mol}^{-1}\right)^{9}$, indicating an equivalent transition state during isopropyl bond rotation (despite the fact that experiments were performed in different solvents). The values for $\Delta H^{\ddagger}$ (37 $\left.\mathrm{kJ} \mathrm{mol}^{-1}\right), \Delta S\left(-75 \mathrm{~J} \mathrm{~mol}^{-1} \mathrm{~K}^{-1}\right)$ and an activation energy of $40 \mathrm{~kJ} \mathrm{~mol}^{-1}$ are somewhat similar to those for NaDIPDTC and PbDIPDTC indicating comparable degrees of $\mathrm{C}-\mathrm{H} \cdots \mathrm{S}$ and steric interactions. Detailed comparisons of these kinetic data were not obtained because of the limited solubility of $\mathbf{1}$ and $\mathbf{2}$ in acetonitrile.

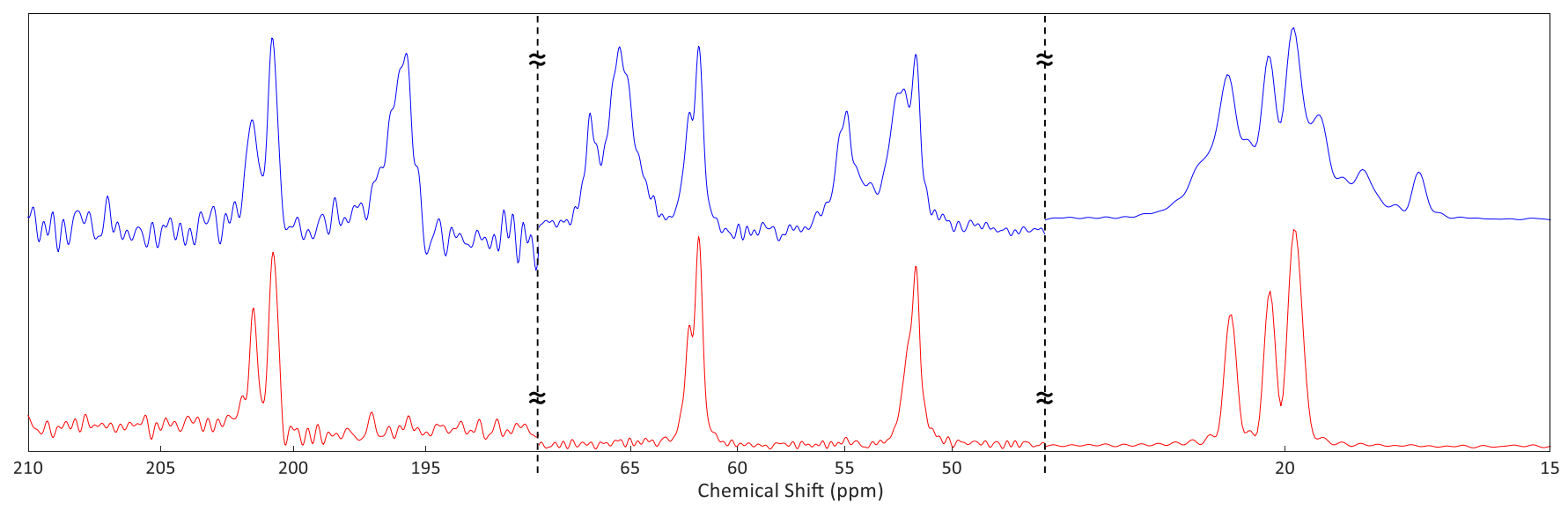

Figure 5: Solid-state ${ }^{13} \mathrm{C}\left\{{ }^{1} \mathrm{H}\right\}$ CPTOSS NMR spectra for $\mathbf{1}$ (bottom) and $\mathbf{2}$ (top) acquired with a MAS rate of $3 \mathrm{kHz}$. Regions devoid of signals are omitted for clarity. 
In contrast to the solution-state spectra, the solid-state ${ }^{13} \mathrm{C}$ CPMAS-TOSS NMR spectra for $\mathbf{1}$ and $\mathbf{2}$ are distinct (Figure 5). The spectra contain signals for each of the carbon atom environments with no impurities detected.

In the spectrum of $\mathbf{1}$, a single set of peaks corresponding to each of the carbon atoms indicates equivalent DIPDTC moieties. As with other DIPDTC complexes, ${ }^{9,57}$ the non-equivalence of the isopropyl environments (due to intramolecular $\mathrm{C}-\mathrm{H} \cdots \mathrm{S}$ hydrogen bonding) ${ }^{11}$ gives rise to two separate methine carbon signals at $\delta_{\mathrm{c}} 51.7$ and $61.8 \mathrm{ppm}$. The dithiocarbamato carbon signal appears at $\delta_{\mathrm{c}} 200.8 \mathrm{ppm}$ and has a slightly higher chemical shift than the corresponding signal in the spectrum of $\mathrm{Pb}$ (DIPDTC $)_{2}{ }^{9}$, likely arising from differential contributions from the $\mathrm{Pb}$ and $\mathrm{Hg}$ bonding orbitals. Three signals appearing between $\delta_{\mathrm{c}} 19.8$ to $21.0 \mathrm{ppm}$ are assigned to nonequivalent methyl groups arising from the presence of intra- and intermolecular $\mathrm{C}-\mathrm{H} \cdots \mathrm{S}$ interactions in the solid state, a phenomenon that has been previously observed. ${ }^{9}{ }^{11}$

In the spectrum of 2, C2, C5, C9 and $\mathrm{C} 12$ are all non-equivalent and give rise to four sets of peaks. Similarly C1 and C8 (196 to 202 ppm) are also non-equivalent, and show different $J$ couplings to the ${ }^{14} \mathrm{~N}$ sites; however, an extra set of signals for each carbon atom is present, indicating that both ligands are not equivalent. In addition to the extra peaks, signals due to disordered diethyl-ether within the matrix are present at $\delta_{\mathrm{c}} 17.5$ and $66.9 \mathrm{ppm}$.

In both cases, all peaks for carbon atoms bonded to nitrogen $(\mathrm{C} 1, \mathrm{C} 8, \mathrm{C} 4, \mathrm{C} 5, \mathrm{C} 9$, and $\mathrm{C} 12)$ are partially split and broadened which we attribute to residual dipolar coupling between ${ }^{14} \mathrm{~N}$ and ${ }^{13} \mathrm{C} .{ }^{58-60}$ In $\mathbf{1}$, the splitting is more pronounced and likely attributed to a longer longitudinal relaxation time constant $\left(T_{1}\right)$ for ${ }^{14} \mathrm{~N}$, or the higher visual crystallinity of $\mathbf{1}$ compared to $\mathbf{2}$. These observations in the solid state ${ }^{13} \mathrm{C}$ NMR acquired using individually isolated (on the basis of morphology) single crystals of $\mathbf{1}$ and $\mathbf{2}$ are supported by comparison to the crystallographic data. 


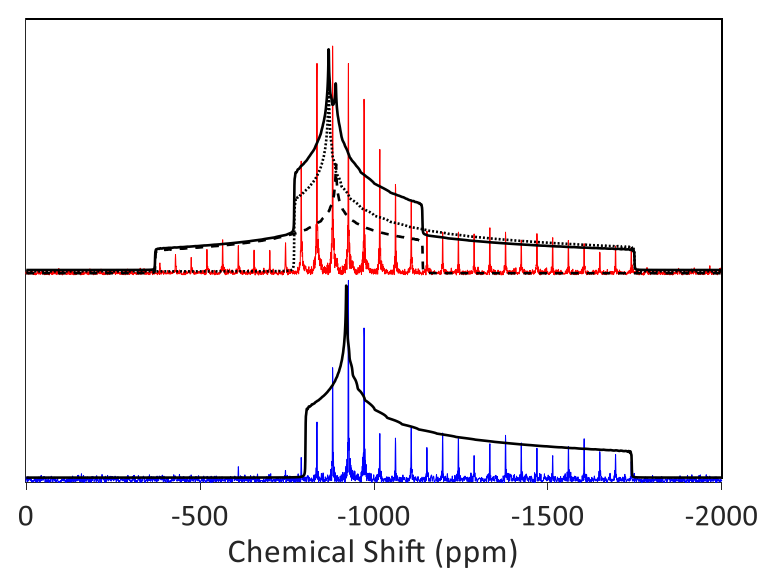

Figure 6: Solid-state ${ }^{1} \mathrm{H}-{ }^{199} \mathrm{Hg}\left\{{ }^{1} \mathrm{H}\right\}$ BRAIN-CP static NMR spectra of crystalline 1 (bottom) and 2 (top). The solid traces show the analytical simulations of the ${ }^{199} \mathrm{Hg}$ spectra for $\mathbf{1}$ and 2. Simulations for the two $\mathrm{Hg}$ environments in $\mathbf{2}$ are represented by a dotted line (site A) and a dashed line (site B).

Table 1: ${ }^{199} \mathrm{Hg}$ NMR parameters for 1 and 2.

\begin{tabular}{lllllll}
\hline & $\delta_{11}$ & $\delta_{22}$ & $\delta_{33}$ & $\delta_{\text {iso }}{ }^{\mathrm{a}}$ & $\Omega^{\mathrm{b}}$ & $\kappa^{\mathrm{c}}$ \\
\hline $\mathbf{1}$ & -802.5 & -920 & -1742.5 & -1155 & 940 & 0.75 \\
& $(26)$ & $(27)$ & $(33)$ & $(20)$ & $(40)$ & $(0.05)$ \\
$\mathbf{2}^{\mathbf{d}}$ & -770.7 & -868.7 & -1750.7 & -1130 & 980 & 0.80 \\
& $(43)$ & $(45)$ & $(48)$ & $(40)$ & $(40)$ & $(0.05)$ \\
& -370.1 & -889.8 & -1140 & -800 & 770 & -0.35 \\
& $(48)$ & $(48)$ & $(46)$ & $(40)$ & $(40)$ & $(0.1)$
\end{tabular}

\footnotetext{
${ }^{\mathrm{a}} \delta_{\text {iso }}=\left(\delta_{11}+\delta_{22}+\delta_{33}\right) / 3^{\mathrm{b}} \Omega=\left|\delta_{33}-\delta_{11}\right|{ }^{\mathrm{c}} \kappa=3\left(\delta_{22}-\delta_{\text {iso }}\right) / \Omega{ }^{\mathrm{d}}$ Multiple signals due to site nonequivalence. The experimental uncertainty in the last digit(s) for each value is indicated in parentheses.

${ }^{199} \mathrm{Hg}$ solid-state NMR experiments were performed using non-spinning crystalline $\mathbf{1}$ and $\mathbf{2}$. The spectra are shown in Figure 6. The chemical shift tensor parameters obtained by analytical simulation of the spikelet patterns for $\mathbf{1}$ and $\mathbf{2}$, are shown in Table 1.
} 
For 1, the simulation revealed a single $\mathrm{Hg}$ site with an isotopic shift $\delta_{\mathrm{Hg}}$ of $-1155 \mathrm{ppm}$, in agreement with the crystal structure where the co-ordination of $\mathrm{Hg}$ is approximated as a highly distorted tetrahedron. The principal components of the chemical shift tensor $\left(\delta_{11}, \delta_{22}\right.$ and $\left.\delta_{33}\right)$ deviate from ideal tetrahedral geometry $\left(\delta_{11}=\delta_{22}=\delta_{33}\right)^{61}$ and the value of the skew $(\kappa)$ indicates a distorted tetrahedral geometry at the $\mathrm{Hg}$ site, consistent with ${ }^{199} \mathrm{Hg}$ chemical shift tensors measured for distorted tetrahedral $\mathrm{Hg}$ environments with multiple $\mathrm{Hg}$-S bonds. ${ }^{46,62}$ In addition, the positive value of $\kappa$ near unity and the local symmetry dictates that the distinct principal component (which also represents the direction of highest shielding), $\delta_{33}$, is oriented along or near the two-fold rotational axis away from the directions of the Hg-S bonds (Figure S6); accordingly, the $\delta_{11}$ and $\delta_{22}$ components are likely directed into similar environments approximately perpendicular to the two-fold rotational axis.

In the case of $\mathbf{2}$, the ${ }^{199} \mathrm{Hg} \mathrm{NMR}$ clearly shows the presence of two patterns corresponding to two distinct sites: $\mathrm{Hg} 1$ (Site A) and $\mathrm{Hg} 2$ (Site B). One pattern has ${ }^{199} \mathrm{Hg}$ chemical shift tensor parameters that are equal (within experimental error) to that of the $\mathrm{Hg}$ site in 1, with a high, positive value for $\kappa$ near unity (Table 1 ). This pattern is assigned to site $\mathrm{A}$, which has a $\mathrm{HgS}_{2}$ environment, with two sets of longer range, secondary $\mathrm{Hg}-\mathrm{S}$ and $\mathrm{Hg}-\mathrm{Cl}$ interactions. As in the case of $\mathbf{1}$, the direction of the $\delta_{33}$ component is very likely along the pseudo two-fold rotational axis, which points in a direction away from the $\mathrm{Hg}-\mathrm{S}$ bonds and between the positions of two nearby chloride ions (Figure S6). The second pattern has a different $\delta_{\text {iso }}$ and a dissimilar set of chemical shift tensor parameters; the negative skew indicates that $\delta_{11}$ is the distinct parameter. This pattern is assigned to site $\mathrm{B}$, which features a unique four-coordinate $\mathrm{HgS}_{2} \mathrm{Cl}_{2}$ environment; unfortunately, since each of the $\mathrm{Hg}-\mathrm{S}$ and $\mathrm{Hg}-\mathrm{Cl}$ bond lengths are distinct, and there are no local symmetry elements, there is no straightforward way to assign the chemical shift tensor orientation based on symmetry ( $a b$ 
initio computations of chemical shift tensors would be useful in this case, but are beyond the scope of the current work).

These assignments on the basis of local symmetry are consistent with the similarity in the mercury sites of $\mathbf{1}$ and $\mathbf{2}$, evidenced in the single crystal X-ray structures (Figures 1 and 3). Having established the patterns of $\mathbf{1}$ and $\mathbf{2}$ using isolated microcrystalline samples, solid-state ${ }^{199} \mathrm{Hg}$ NMR experiments confirmed that $\mathbf{1}$ and $\mathbf{2}$ did not interconvert during crystal growth (Video 1 ) of isolated 1 (on the basis of ${ }^{199} \mathrm{Hg}$ SSNMR).

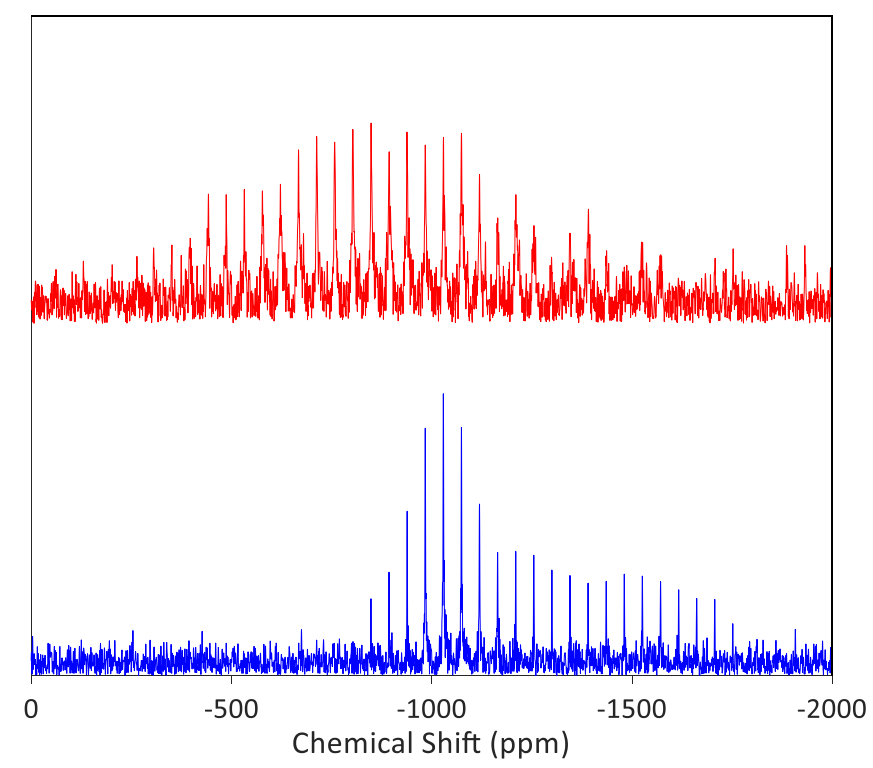

Figure 7: Solid-state ${ }^{199} \mathrm{Hg}\left\{{ }^{1} \mathrm{H}\right\}$ BRAIN-CP NMR spectra of powdered 1 (bottom) and 2 (top) prior to crystal growth.

The solid-state ${ }^{199} \mathrm{Hg}$ NMR spectra of $\mathbf{1}$ and $\mathbf{2}$ prior to crystal growth experiments show significant differences between the powders (Figure 7) indicating both different numbers and types of mercury environments, which were formed on the basis of ligand to metal reaction stoichiometry. Previous studies using a small excess of ligand (2.1:1 ligand to metal ratio) produced monomer and dimer without any 2 being detected..$^{50}$ Differences in relative spikelet intensities before and after crystallisation are attributed to changes in the physical sample 
morphology (though it is noted that these spectra cannot be used for quantitative interpretation without careful calibration of known standards). In the case of $\mathbf{2}$, the spectra before and after are noticeably different, which we attribute to differences in the molecular conformation and different physical sample morphology instigated by the incorporation of ether, which occurs during the crystal growth (indicated by disordered ether molecules within the crystal structure of 2).

The FTIR spectra of $\mathbf{1}$ and $\mathbf{2}$ are shown in Figure S8 and are similar to each other. The spectra show the typical thioureide band at $1495 \mathrm{~cm}^{-1}$, which is at an energy intermediate between that of a $\mathrm{C}-\mathrm{N}$ single bond $\left(1250-1350 \mathrm{~cm}^{-1}\right)$ and a $\mathrm{C}=\mathrm{N}$ double bond $\left(1640-1690 \mathrm{~cm}^{-1}\right)$. The $v(\mathrm{C} \ldots \mathrm{S})$ band appears at $922 \mathrm{~cm}^{-1}$. These bands are within $\sim 15 \mathrm{~cm}^{-1}$ of the corresponding bands for $\mathrm{Pb}(\text { DIPDTC })_{2}{ }^{9} \mathrm{NaDIPDTC}^{9}$ and $\mathrm{Ni}(\mathrm{DIPDTC})_{2} \cdot{ }^{10}$

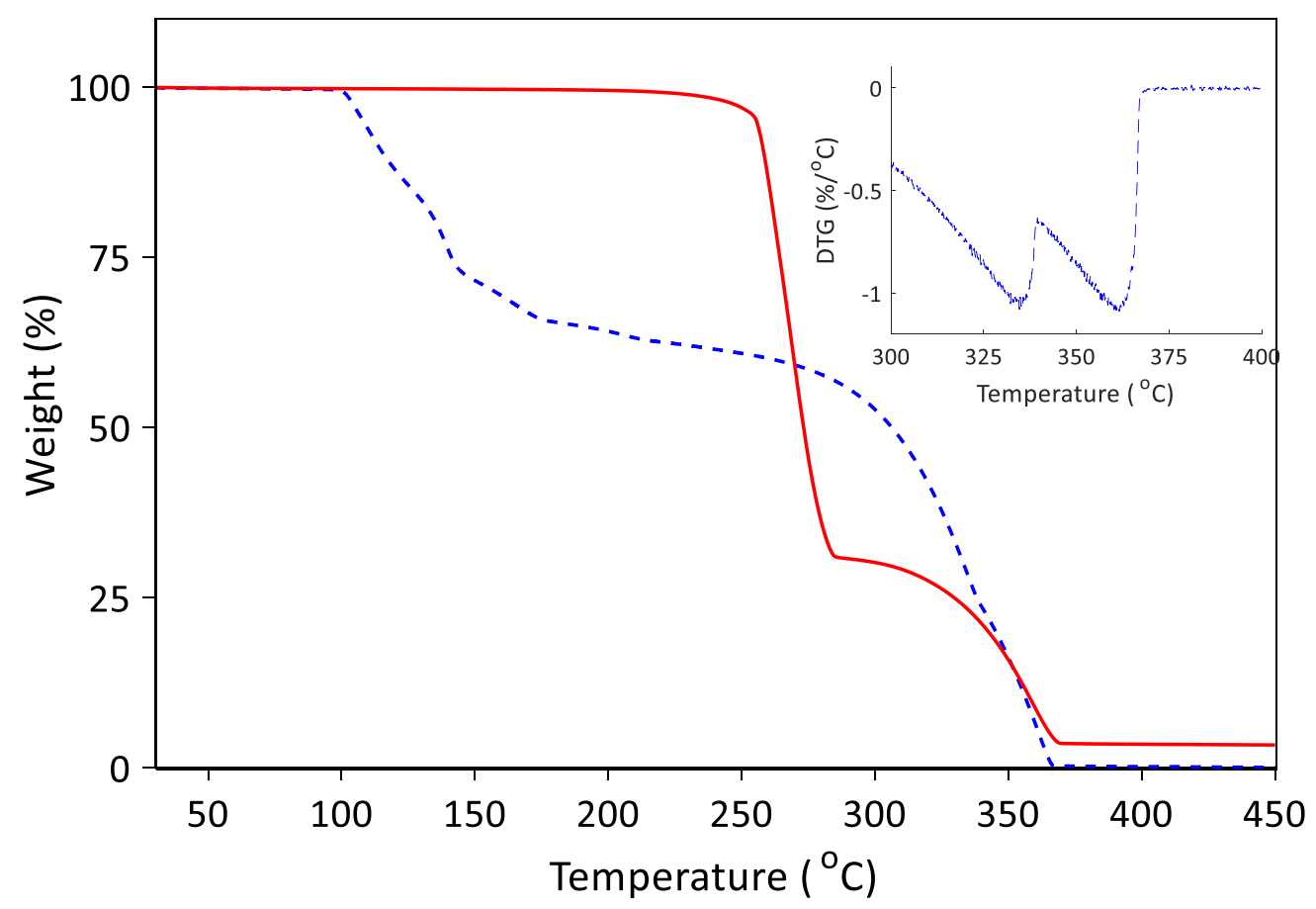

Figure 8: Thermogravimetric data for $\mathbf{1}$ (red solid line) and $\mathbf{2}$ (blue dashed line). Inset shows the first derivative of mass loss between 300 to $400{ }^{\circ} \mathrm{C}$. 
Thermogravimetric analysis data are shown in Figure 8, and reveal distinct pathways for thermal decomposition. Analysis of 1 reveals no significant mass loss in the region of $30-100{ }^{\circ} \mathrm{C}$ indicating a lack of water (bound or otherwise), in agreement with the crystallographic data. Thermal decomposition occurs in two endothermic events. The first event occurs between $230-285{ }^{\circ} \mathrm{C}$ with a $\mathrm{DTG}_{\max }$ at $268{ }^{\circ} \mathrm{C}$ and a mass loss of $69 \%$, which we assign to the formation of $\mathrm{HgS}$ (calculated mass loss: 58\%). The second event occurs between $285-370{ }^{\circ} \mathrm{C}$ with a $\mathrm{DTG}_{\max }$ at 360 ${ }^{\circ} \mathrm{C}$ and a mass loss of $28 \%$ corresponding to the thermolysis of $\mathrm{HgS}$ into mercury vapour and sulfur (calculated mass loss: $42 \%$ ). The significant discrepancies between observed and calculated mass losses are due to the overlap of complex decomposition and the onset of $\mathrm{HgS}$ decomposition. ${ }^{50,63}$ Thermogravimetric analysis of 2 shows no significant mass loss below $100^{\circ} \mathrm{C}$, again indicating a lack of water (bound or otherwise). Thermal decomposition occurs in six well-defined endothermic events, with the first four occurring between $96-218{ }^{\circ} \mathrm{C}$ with an associated mass loss of $38.3 \%$, in excellent agreement with the calculated loss of all ligands to produce $\mathrm{HgS}$ and $\mathrm{HgCl}_{2}(38.2 \%)$. There are two overlapping mass loss events between 240 to $340{ }^{\circ} \mathrm{C}$ attributed to the thermal decomposition of $\mathrm{HgS}$ into mercury vapour and sulfur ${ }^{63}$, and the sublimation of $\mathrm{HgCl}_{2}$ at $\sim 280{ }^{\circ} \mathrm{C} .{ }^{64}$

The marked difference in thermal behaviour between $\mathbf{1}$ and $\mathbf{2}$ is attributed to the different coordination environments about each mercury atom. In $\mathbf{1}, \mathrm{Hg}$ is chelated by the DIPDTC ligands forming $\mathrm{HgS}_{4}$ moieties, whereas in $\mathbf{2}$ there is a mixture of $\mathrm{HgS}_{2}$ and $\mathrm{HgS}_{2} \mathrm{Cl}_{2}$ centers. Moreover, these results show that neither $\mathbf{1}$ nor $\mathbf{2}$ is a suitable single-source precursor for the synthesis of $\mathrm{HgS}$ nanocrystals, as the decomposition of $\mathbf{1}$ occurs simultaneously with that of $\mathrm{HgS}$, and in the case of 2, $\mathrm{HgS}$ is obtained as a mixture with $\mathrm{HgCl}_{2}$. Comparison of these data with thermal data for other 
mercury(II) dithiocarbamate complexes ${ }^{19}, 32$ suggests that further investigation of $\mathbf{1}$ under conditions that utilize a chemical passivating agent (e.g., hexadecylamine) is warranted.

\section{Conclusions}

The product obtained from reaction of sodium di-isopropyldithiocarbamate with $\mathrm{HgCl}_{2}$ in water is dependent upon the reaction stoichiometry. The known monomeric $\mathrm{Hg}(\mathrm{DIPDTC})_{2}$ complex was formed when the ligand was present in excess as distinct from when the metal was in excess, and a new polymeric mercury(II) dithiocarbamate was discovered. Surprisingly, the solution phase NMR spectra and FTIR spectra provided no basis upon which the two complexes could be distinguished from each other. Solid-state NMR spectroscopy $\left({ }^{199} \mathrm{Hg}\right.$ and $\left.{ }^{13} \mathrm{C}\right)$ and single crystal diffraction provided data that enabled the two complexes to be differentiated. These data were vital to establish that the monomeric (1) and polymeric (2) complexes do not interconvert in solution or during crystal growth.

Thermogravimetric experiments revealed different thermal decomposition behaviour between the two compounds, with neither deemed to be suitable as a single source precursor for $\mathrm{HgS}$ formation.

\section{Experimental}

General: Caution! Mercury compounds are toxic, and appropriate precautions should be taken.

De-ionized water was used in synthetic procedures. All chemicals and solvents used in synthetic procedures were analytical grade and purchased from Sigma Aldrich and used as received. Sodium di(isopropyl)dithiocarbamate pentahydrate was prepared as previously described. ${ }^{10}$ Product yields were calculated with respect to the limiting reagent, which was $\mathrm{HgCl}_{2}$ in the case of $\mathbf{1}$, and sodium di(isopropyl)dithiocarbamate in the case of 2. FTIR spectra were acquired using a Nicolet 6700 
FTIR spectrometer with a diamond iTX ATR accessory. A Thermal Advantage SDT-Q600 thermal analyzer was used to simultaneously obtain thermogravimetric (TG) and differential scanning calorimetry (DSC) data using $90 \mu \mathrm{L}$ alumina crucibles. Experiments were conducted under an atmosphere of nitrogen gas $\left(150 \mathrm{~mL} \mathrm{~min}{ }^{-1}\right)$ and a heating rate of $10{ }^{\circ} \mathrm{C} \min ^{-1}$ over a temperature range of 30 to $450{ }^{\circ} \mathrm{C}$. High-resolution mass spectrometry was performed using an Agilent 6510 Q-TOF with a mobile phase of $70 \%$ acetonitrile, $30 \%$ water (with $0.01 \%$ formic acid) and a flow rate of $0.5 \mathrm{~mL} \mathrm{~min}{ }^{-1}$. Variable-temperature NMR spectroscopy using a mixture of $\mathbf{1}$ and $\mathbf{2}$ in chloroform- $d$ was performed using a Bruker Avance III NMR spectrometer fitted with a BBFO Plus solution-state probe and a BCU-Xtreme cooler. The frequency was $600.1 \mathrm{MHz}$ for ${ }^{1} \mathrm{H}$ and 150.9 MHz for ${ }^{13} \mathrm{C}$. The sample temperature was calibrated using a Type $\mathrm{K}$ thermocouple in an NMR tube containing ethanol that was inserted into the probe. Instrument broadening was accounted for using the full width at half-maximum (fwhm) of chloroform- $d$ residual proton resonances. With these data, experimental rate constants were calculated at each temperature using the fwhm of the methyl peak at $1.63 \mathrm{ppm}$. Arrhenius and Eyring activation parameters were obtained using generalized least-squares linear regressions of $\log k$ versus $1 / T$, and $\log (k / T)$ versus $1 / T$ respectively. Solid-state ${ }^{199} \mathrm{Hg}$ and ${ }^{13} \mathrm{C}$ NMR spectra were acquired using a Bruker Avance III solid-state NMR spectrometer with a 7 Tesla superconducting magnet operating at frequencies of 53.62 MHz, $75.37 \mathrm{MHz}$, and $299.75 \mathrm{MHz}$ for the ${ }^{199} \mathrm{Hg},{ }^{13} \mathrm{C}$ and ${ }^{1} \mathrm{H}$ nuclei respectively. The crystalline samples were acquired by manual separation of crystals produced from crystal growth experiments. Candidate crystals of $\mathbf{1}$ and $\mathbf{2}$ were separated on the basis of their morphology and periodically checked using unit cell analysis by single crystal X-ray diffraction. Specimens were loaded into $4 \mathrm{~mm}$ zirconia rotors fitted with Kel-F caps and packed with Teflon tape. The solidstate ${ }^{13} \mathrm{C}$ NMR spectra were acquired with the CP-TOSS pulse program at a spinning speed of 3 
kHz MAS, and a cross-polarization contact time of $1 \mathrm{~ms}$, and SPINAL- $64{ }^{1} \mathrm{H}$ decoupling with a $80 \mathrm{kHz}$ decoupling field strength during acquisition. The ${ }^{199} \mathrm{Hg}$ NMR spectra were acquired under static conditions, using the BRAIN $\mathrm{CP}^{65}$ method, with a 25 -ms broadband adiabatic pulse for polarization transfer, coupled with the WURST-CPMG ${ }^{66}$ pulse sequence during detection for signal enhancement. The envelope of the resulting "spikelet" pattern yields the anisotropic lineshape of the ${ }^{199} \mathrm{Hg}$ NMR spectrum and was modelled by Sola using Bruker's Topspin software. The experimental uncertainties in the principal components of the chemical shift tensor were estimated using WSOLIDS software, ${ }^{67}$ using bidirectional variation of each parameter and visual comparison of the experimental and simulated spectra; uncertainties in $\delta_{\text {iso, }}, \Omega$, and $\kappa$ were than calculated using standard propagation of error methods.

\section{Single Crystal X-ray diffraction:}

Suitable single crystals were selected using a Leica M165Z polarizing microscope and mounted on a MiTiGen MicroMount. X-ray diffraction measurements were made using a Bruker Kappa-II CCD diffractometer at $150 \mathrm{~K}$ using a I $\mu \mathrm{S}$ Incoatec Microfocus Source and Mo-K $\alpha$ radiation $(\lambda=$ $1.710723 \AA$ ). The structures were solved using charge flipping and the full matrix least squares refinement was performed using ShelX $1^{68}$ in Olex $2^{69}$. Heavy atoms were refined isotropically until R-factor convergence, and then an anisotropic model was applied. Where possible, hydrogen atoms were located using a difference Fourier plot, or restrained to neutron diffraction distances when required. Bond angles were kept to two decimal places, and bond lengths to three.

\section{Optical Photomicroscopy:}

Optical photomicroscopy was performed using a Zeiss Stemi-305 stereomicroscope operating in a cross polarized light configuration. Photomicrographs were acquired using a Q-Imaging 
MicroPublisher 3.3RTV CCD camera. Time-Lapse of crystal growth was performed using an insitu chamber made in house with photomicrographs acquired in 10 minute intervals.

\section{Synthesis:}

Synthesis of bis( $\kappa^{2} \mathrm{~S}, \mathrm{~S}^{\prime}-\mathrm{di}($ isopropyl)dithiocarbamato)mercury(II) (1): An aqueous solution of sodium di(isopropyl)dithiocarbamate $(1.012 \mathrm{~g}, 3.50 \mathrm{mmol}$, in $100 \mathrm{~mL}$ of water) was added dropwise to an aqueous solution of mercury (II) chloride ( $0.312 \mathrm{~g}, 1.15 \mathrm{mmol}$, in $100 \mathrm{~mL}$ of water). A white precipitate formed upon addition and the suspension was stirred for 2 min. The crude product was collected by vacuum filtration, and the filter cake was repeatedly triturated with water to produce a white paste which was dried in vacuo at $45{ }^{\circ} \mathrm{C}$ to yield $0.522 \mathrm{~g}$ of 1 (82\%). Crystals suitable for X-ray analysis were obtained as pale yellow tabular plates by solvent counterdiffusion of ether into a solution of 1 in chloroform. ${ }^{1} \mathrm{H}$ NMR $\left(600.1 \mathrm{MHz}, \mathrm{CDCl}_{3}, 238 \mathrm{~K}\right): \delta 5.15\left(\mathrm{sept},{ }^{3} \mathrm{~J}_{\mathrm{HH}}\right.$ $\left.=6.6 \mathrm{~Hz},{ }^{1} \mathrm{~J}_{\mathrm{CH}}=140 \mathrm{~Hz}, 2 \mathrm{H}, \mathrm{C} 2 \mathrm{H}, \mathrm{C} 2 \mathrm{H}^{\prime}\right), 3.88\left(\mathrm{sept},{ }^{3} \mathrm{~J}_{\mathrm{HH}}=6.8 \mathrm{~Hz},{ }^{1} \mathrm{~J}_{\mathrm{CH}}=136 \mathrm{~Hz}, 2 \mathrm{H}, \mathrm{C} 5 \mathrm{H}, \mathrm{C} 5 \mathrm{H}^{\prime}\right)$, $1.63\left(\mathrm{~d}^{3}{ }^{3} \mathrm{~J}_{\mathrm{HH}}=6.8 \mathrm{~Hz},{ }^{1} \mathrm{~J}_{\mathrm{CH}}=128 \mathrm{~Hz}, 12 \mathrm{H}, \mathrm{C} 6 \mathrm{H} 3, \mathrm{C} 6 \mathrm{H} 3{ }^{\prime}, \mathrm{C} 7 \mathrm{H} 3, \mathrm{C} 7 \mathrm{H} 3{ }^{\prime}\right), 1.27\left(\mathrm{~d},{ }^{3} \mathrm{~J}_{\mathrm{HH}}=6.6 \mathrm{~Hz}\right.$, $\left.{ }^{1} \mathrm{~J}_{\mathrm{CH}}=128 \mathrm{~Hz}, 12 \mathrm{H}, \mathrm{C} 3 \mathrm{H} 3, \mathrm{C} 3 \mathrm{H} 3{ }^{\prime}, \mathrm{C} 4 \mathrm{H} 3, \mathrm{C} 4 \mathrm{H} 3{ }^{\prime}\right) .{ }^{13} \mathrm{C} \mathrm{NMR}\left(150.9 \mathrm{MHz}, \mathrm{CDCl}_{3}, 238 \mathrm{~K}\right): \delta 202.0$ (C1,C1'), 62.3 (C2,C2'), $51.4\left(\mathrm{C} 5, \mathrm{C} 5^{\prime}\right), 19.8$ (C6,C7,C6',C7'), 19.5 (C3,C4,C3',C4'). ${ }^{15} \mathrm{~N}$ NMR $\left(60.8 \mathrm{MHz}, \mathrm{CDCl}_{3}, 238 \mathrm{~K}\right): \delta 190.3\left(\mathrm{~N} 1, \mathrm{~N} 1{ }^{\prime}\right) .{ }^{13} \mathrm{C}\left\{{ }^{1} \mathrm{H}\right\}(3.0 \mathrm{KHz}, 293 \mathrm{~K}): \delta 202-200(\mathrm{C} 1, \mathrm{C} 1$ '), $63-61$ (C2,C2'), $53-51$ (C5,C5'), $22-19$ (C3,C3',C4,C4',C6,C6',C7,C7'). ${ }^{199} \mathrm{Hg}\left\{{ }^{1} \mathrm{H}\right\}$ (Static, $293 \mathrm{~K}): \delta-1170(\mathrm{Hg} 1)$. (HRMS) $(\mathrm{M}+\mathrm{H})^{+}$for $\mathrm{HgN}_{2} \mathrm{~S}_{4} \mathrm{C}_{14} \mathrm{H}_{28}$ Calculated: 555.0908; Observed 555.0888; Difference: $3.6 \mathrm{ppm}$.

Synthesis of bis( $\kappa^{2} \mathrm{~S}, \mathrm{~S}^{\prime}$-di(isopropyl)dithiocarbamato)mercury(II). $\mathrm{HgCl}_{2}$ (2):

An aqueous solution of sodium di(isopropyl)dithiocarbamate $(0.110 \mathrm{~g}, 0.38 \mathrm{mmol}$, in $100 \mathrm{~mL}$ of water) was added with stirring to a solution of mercury (II) chloride $(0.313 \mathrm{~g}, 1.15 \mathrm{mmol}$, in $100 \mathrm{~mL}$ of water). A pale yellow precipitate formed and the mixture was stirred vigorously for 2 
min. The crude product was collected by vacuum filtration and the filter cake was repeatedly washed with water then dried at $45{ }^{\circ} \mathrm{C}$ in vacuo to produce $0.236 \mathrm{~g}$ of $2(75 \%)$ as a pale yellow powder. Crystals suitable for X-ray analysis were acquired as radial prismatic clusters by solvent counter diffusion of ether into a solution of $\mathbf{2}$ in chloroform. ${ }^{13} \mathrm{C}\left\{{ }^{1} \mathrm{H}\right\}(3.0 \mathrm{KHz}, 293 \mathrm{~K}): \delta 202-$ 196 (C1, C8), 68 - 60 (C5,C12), 56 - 51 (C2,C9), 23 - 17 (C3, C4,C6,C7,C10,C11,C13,C14). ${ }^{199} \mathrm{Hg}\left\{{ }^{1} \mathrm{H}\right\}$ (Static, $\left.293 \mathrm{~K}\right): \delta$-1129 (Hg1), -799 (Hg2).

Supporting Information. The following files are available free of charge. Relevant crystallographic and NMR data. CCDC 1858161, 1858163 and 1858175, and video showing counter-diffusion..

\section{Corresponding Author}

* andrew.mcdonagh@uts.edu.au

\section{Author Contributions}

The manuscript was written through contributions of all authors. All authors have given approval to the final version of the manuscript.

\section{Acknowledgement}

We gratefully acknowledge Dr Ronald Shimmon for laboratory assistance. We are in gratitude to the Mark Wainwright Analytical Center, UNSW, for access to single crystal XRD, and NMR spectrometers, supported by ARC funding, LE0989541 for NMR equipment. This research is

supported by an Australian Government Research Training Program Scholarship and the Natural Sciences and Engineering Research Council (NSERC, Canada).

\section{References}


1. Howie, R. A.; Tiekink, E. R. T.; Wardell, J. L.; Wardell, S. M. S. V., Complementary Supramolecular Aggregation via $\mathrm{O}-\mathrm{H} \cdots \mathrm{O}$ Hydrogen-bonding and $\mathrm{Hg} \cdots \mathrm{S}$ Interactions in Bis[N,N'-di(2-hydroxyethyl)-dithiocarbamato-S, $\left.\mathrm{S}^{\prime}\right]$ mercury(II): $\mathrm{Hg}\left[\mathrm{S}_{2} \mathrm{CN}\left(\mathrm{CH}_{2} \mathrm{CH}_{2} \mathrm{OH}\right)_{2}\right]_{2} . J$. Chem. Crystallogr. 2009, 39, 293-298.

2. Hogarth, G., Metal-dithiocarbamate complexes: chemistry and biological activity. MiniRev. Med. Chem. 2012, 12, 1202-15.

3. Andrew, F. P.; Ajibade, P. A., Metal complexes of alkyl-aryl dithiocarbamates: Structural studies, anticancer potentials and applications as precursors for semiconductor nanocrystals. $J$. Mol. Struct. 2018, 1155, 843-855.

4. Cookson, J.; Beer, P. D., Exploiting the dithiocarbamate ligand in metal-directed selfassembly. Dalton Trans. 2007, 1459-72.

5. Hogarth, G., Transition Metal Dithiocarbamates: 1978-2003. In Prog. Inorg. Chem., Karlin, K. D., Ed. John Wiley \& Sons, Inc.: 2005; Vol. 53.

6. Tiekink, E. R., Influence of crystal structure on molecular structure: Syntactic structural chemistry. Rigaku J 2002, 19, 14-24.

7. Liu, Y.; Tiekink, E. R., Supramolecular associations in binary antimony (III) dithiocarbamates: Influence of ligand steric bulk, influence on coordination geometry, and competition with hydrogenbonding. CrystEngComm 2005, 7, 20-27.

8. Tiekink, E. R., Molecular architecture and supramolecular association in the zinc-triad 1, 1-dithiolates. Steric control as a design element in crystal engineering? CrystEngComm 2003, 5, 101-113.

9. Angeloski, A.; Gentle, A. R.; Scott, J. A.; Cortie, M. B.; Hook, J. M.; Westerhausen, M. T.; Bhadbhade, M.; Baker, A. T.; McDonagh, A. M., From Lead(II) Dithiocarbamate Precursors to a Fast Response PbS Positive Temperature Coefficient Thermistor. Inorg. Chem. 2018, 57, 2132-2140.

10. Angeloski, A.; Baker, A. T.; Bhadbhade, M.; McDonagh, A. M., Bis(к2S,S'di(isopropyl)dithiocarbamato)nickel(II): Anagostic $\mathrm{C}-\mathrm{H} \cdots \mathrm{Ni}$ interactions and physical properties. J. Mol. Struct. 2016, 1113, 127-132.

11. Angeloski, A.; Hook, J. M.; Bhadbhade, M.; Baker, A. T.; McDonagh, A. M., Intramolecular $\mathrm{H} \cdots \mathrm{S}$ interactions in metal di-(isopropyl)dithiocarbamate complexes. CrystEngComm 2016, 18, 7070-7077.

12. Golding, R. M.; Healy, P. C.; Newman, P. W. G.; Sinn, E.; White, A. H., Temperature dependence of the proton nuclear magnetic resonance spectra of some diamagnetic N,Ndialkyldithiocarbamate complexes of transition metals. Inorg. Chem. 1972, 11, 2435-2440.

13. Lindmark, A. F.; Fay, R. C., Kinetics of hindered Rotation about Carbon-Nitrogen Single Bonds in Some N,N-diisopropyldithiocarbamates. Inorg. Chem. 1983, 22, 2000-2006.

14. Takeda, Y.-I.; Watanabe, N.; Tanaka, T., Barrier to internal rotation around isopropylnitrogen bond of some N,N-di-isopropyldithio-and -diselenocarbamate complexes of tin (IV), $\mathrm{X}_{2} \mathrm{Sn}\left[\mathrm{Y}_{2} \mathrm{CN}(\mathrm{Pr}-\mathrm{i})_{2}\right]_{2}(\mathrm{X}=\mathrm{Cl}, \mathrm{Me} ; \mathrm{Y}=\mathrm{S}, \mathrm{Se})$. Spectrochim. Acta, Part A 1976, 32, 1553-1556. 15. Bhattacharya, S.; Kanungo, B. K.; Sahoo, S., Synthesis, characterization and dynamic stereochemistry of thermochromic tris(dithiocarbamato)vanadium(III) complexes. J. Coord. Chem. 2006, 59, 371-378.

16. Bhat, A. N.; Fay, R. C.; Lewis, D. F.; Lindmark, A. F.; Strauss, S. H., Preparation and characterization of some six-, seven-, and eight-coordinate titanium(IV) N, Ndialkyldithiocarbamates. Inorg. Chem. 1974, 13, 886-892. 
17. Benson, R. E.; Ellis, C. A.; Lewis, C. E.; Tiekink, E. R. T., 3D-, 2D- and 1Dsupramolecular structures of $\left\{\mathrm{Zn}\left[\mathrm{S}_{2} \mathrm{CN}\left(\mathrm{CH}_{2} \mathrm{CH}_{2} \mathrm{OH}\right) \mathrm{R}\right]_{2}\right\}_{2}$ and their

$\left\{\mathrm{Zn}\left[\mathrm{S}_{2} \mathrm{CN}\left(\mathrm{CH}_{2} \mathrm{CH}_{2} \mathrm{OH}\right) \mathrm{R}\right]_{2}\right\}_{2}$ (4,4'-bipyridine) adducts for $\mathrm{R}=\mathrm{CH}_{2} \mathrm{CH}_{2} \mathrm{OH}$, Me or Et: polymorphism and pseudo-polymorphism. CrystEngComm 2007, 9, 930-940.

18. Roffey, A.; Hollingsworth, N.; Islam, H. U.; Mercy, M.; Sankar, G.; Catlow, C. R.; Hogarth, G.; de Leeuw, N. H., Phase control during the synthesis of nickel sulfide nanoparticles from dithiocarbamate precursors. Nanoscale 2016, 8, 11067-11075.

19. Ajibade, P. A.; Mbese, J. Z.; Omondi, B., Group 12 dithiocarbamate complexes: Synthesis, characterization, and X-ray crystal structures of $\mathrm{Zn}$ (II) and $\mathrm{Hg}$ (II) complexes and their use as precursors for metal sulfide nanoparticles. Inorg. Nano-Met. Chem. 2016, 47, 202-212. 20. Prakasam, B. A.; Lahtinen, M.; Peuronen, A.; Muruganandham, M.; Kolehmainen, E.; Haapaniemi, E.; Sillanpää, M., Spectral and structural studies on Ni(II) dithiocarbamates: Nickel sulfide nanoparticles from a dithiocarbamate precursor. Inorg. Chim. Acta 2015, 425, 239-246. 21. Gomathi, G.; Dar, S. H.; Thirumaran, S.; Ciattini, S.; Selvanayagam, S., Bis(N-benzyl-Nfurfuryldithiocarbamato-S,S')mercury(II) as a precursor for the preparation of mercury sulfide nanoparticles. Comptes Rendus Chimie 2015, 18, 499-510.

22. Chintso, T.; Ajibade, P. A., Synthesis and structural studies of hexadecylamine capped lead sulfide nanoparticles from dithiocarbamate complexes single source precursors. Mater. Lett. 2015, 141, 1-6.

23. Sathiyaraj, E.; Gurumoorthy, G.; Thirumaran, S., Nickel(II) dithiocarbamate complexes containing the pyrrole moiety for sensing anions and synthesis of nickel sulfide and nickel oxide nanoparticles. New J. Chem. 2015, 39, 5336-5349.

24. Hollingsworth, N.; Roffey, A.; Islam, H.-U.; Mercy, M.; Roldan, A.; Bras, W.; Wolthers, M.; Catlow, C. R. A.; Sankar, G.; Hogarth, G.; de Leeuw, N. H., Active Nature of Primary Amines during Thermal Decomposition of Nickel Dithiocarbamates to Nickel Sulfide Nanoparticles. Chem. Mater. 2014, 26, 6281-6292.

25. Nemati, F.; Ghorbani Gharjeh Ghiyaei, A.; Notash, B.; Shayegan, M. H.; Amani, V., A rapid and convenient synthesis of gem-bis(dithiocarbamate) derivatives from primary aliphatic amines, carbon disulfide, and aromatic aldehydes using boron trifluoride-diethyl etherate.

Tetrahedron Lett. 2014, 55, 3572-3575.

26. Ehsan, M. A.; Peiris, T. A.; Wijayantha, K. G.; Olmstead, M. M.; Arifin, Z.; Mazhar, M.; Lo, K. M.; McKee, V., Development of molecular precursors for deposition of indium sulphide thin film electrodes for photoelectrochemical applications. Dalton Trans 2013, 42, 10919-28.

27. Sivagurunathan, G. S.; Ramalingam, K.; Rizzoli, C., Nanothallium(III) sulfide from dithiocarbamate precursors: Synthesis, single crystal X-ray structures and characterization. Polyhedron 2013, 65, 316-321.

28. Ramasamy, K.; Kuznetsov, V. L.; Gopal, K.; Malik, M. A.; Raftery, J.; Edwards, P. P.; O'Brien, P., Organotin Dithiocarbamates: Single-Source Precursors for Tin Sulfide Thin Films by Aerosol-Assisted Chemical Vapor Deposition (AACVD). Chem. Mater. 2013, 25, 266-276.

29. Li, P.; Li, H.; Jie, W., Preparation of lanthanum sulfide nanoparticles by thermal decomposition of lanthanum complex. J. Rare Earths 2011, 29, 317-320.

30. Jen-La Plante, I.; Zeid, T. W.; Yang, P.; Mokari, T., Synthesis of metal sulfide nanomaterials via thermal decomposition of single-source precursors. J. Mater. Chem. 2010, 20, 6612 . 
31. An, G.; Chenguang, L.; Hou, Y.; Zhang, X.; Liu, Y., Transition metal dichalcogenide materials: Solid-state reaction synthesis of nanocrystalline nickel disulfide. Mater. Lett. 2008, 62, 2643-2646.

32. Gurumoorthy, G.; Thirumaran, S.; Ciattini, S., Unusual octahedral Hg(II) dithiocarbamate: Synthesis, spectral and structural studies on $\mathrm{Hg}$ (II) complexes with pyrrole based dithiocarbamates and their utility for the preparation of $\alpha$ - and $\beta-\mathrm{HgS}$. Polyhedron 2016, $118,143-153$.

33. Cookson, J.; Beer, P. D., Exploiting the dithiocarbamate ligand in metal-directed selfassembly. Dalton Trans. 2007, 1459-1472.

34. Book, L.; Chieh, C., The structure of catena- $\{\mathrm{di}-[\mu]$-chloro-tetrakis $[[\mu]-(\mathrm{N}, \mathrm{N}-$ diethyldithiocarbamato-S,S')] trimercury(II)\}, $\left[\mathrm{Hg}_{3}\left(\mathrm{C}_{5} \mathrm{H}_{10} \mathrm{NS}_{2}\right)_{4} \mathrm{Cl}_{2}\right]$. Acta Crystallogr. Sect. $B$ 1980, 36, 300-303.

35. Iwasaki, H., Crystal structure of dichloro-tetrakis(diethyldithiocarbamato)trimercury, $\mathrm{Hg}_{3} \mathrm{Cl}_{2}\left(\mathrm{~S}_{2} \mathrm{CNEt}_{2}\right)_{4}$. Chem. Lett. 1972, 1, 1105-1106.

36. Bond, A. M.; Colton, R.; Hollenkamp, A. F.; Hoskins, B. F.; McGregor, K.; Tiekink, E. R. T., An unexpected stoichiometric effect in both solution and solid state in mercury-rich dithiocarbamate cation chemistry: crystal and molecular structure of polymeric tris(piperidinecarbodithioato)dimercury(II) perchlorate. Inorg. Chem. 1991, 30, 192-197. 37. Healy, P. C.; White, A. H., Crystal structure of bis(NNdiethyldithiocarbamato)mercury(II). J. Chem. Soc., Dalton Trans. 1973, 284-287.

38. Kobayashi, N.; Fujisawa, T., The Reactions of Sodium Diethyldithiocarbamate and Tetraethylthiuram Disulfide with Mercury(II) Chloride. Bull. Chem. Soc. Jpn. 1976, 49, 27802783.

39. House, D. A.; Robinson, W. T.; McKee, V., Chloromercury(II) anions. Coord. Chem. Rev. 1994, 135-136, 533-586.

40. Okuniewski, A.; Rosiak, D.; Chojnacki, J.; Becker, B., Coordination polymers and molecular structures among complexes of mercury(II) halides with selected 1-benzoylthioureas. Polyhedron 2015, 90, 47-57.

41. Englert, U., Halide-bridged polymers of divalent metals with donor ligands - structures and properties. Coord. Chem. Rev. 2010, 254, 537-554.

42. Guzmán-Percástegui, E.; Zakharov, L. N.; Alvarado-Rodríguez, J. G.; Carnes, M. E.; Johnson, D. W., Synthesis of a Self-Assembled Hg(II)-Dithiocarbamate Metallomacrocycle. Cryst. Growth Des. 2014, 14, 2087-2091.

43. Morsali, A.; Masoomi, M. Y., Structures and properties of mercury(II) coordination polymers. Coord. Chem. Rev. 2009, 253, 1882-1905.

44. Levason, W.; McAuliffe, C., The Chemistry of Mercury. 1st ed.; Palgrave Macmillan UK: 1977.

45. Sahebalzamani, H.; Ghammamy, S.; Mehrani, K.; Salimi, F., Synthesis, characterization and thermal analysis of $\mathrm{Hg}$ (II) complexes with hydrazide ligands. Der Chemica Sinica 2010, 1, 67.

46. Safin, D. A.; Holmberg, R. J.; Burgess, K. M. N.; Robeyns, K.; Bryce, D. L.; Murugesu, M., Hybrid Material Constructed from $\mathrm{Hg}(\mathrm{NCS})_{2}$ and 2,4,6-Tris(2-pyrimidyl)-1,3,5-triazine (TPymT): Coordination of TPymT in a 2,2'-Bipyridine-Like Mode. Eur. J. Inorg. Chem. 2015, 2015, 441-446.

47. Khavasi, H. R.; Mohammad Sadegh, B. M., Temperature-Dependent Supramolecular Motif in Coordination Compounds. Inorg. Chem. 2010, 49, 5356-5358. 
48. Ito, M.; Iwasaki, H., The Structure of the Monomeric Form of Mercury(l1) N,NDiisopropyldithiocarbamate [Bis(N,N-diisopropyldithiocarbamato)mercury(II)]. Acta Crystallograph. Sect. B 1979, 35, 2720-2721.

49. Iwasaki, H.; Ito, M.; Kobayashi, K., Coexistence of monomeric and dimeric complex molecules in a crystal: The crystal structure of the $\beta$-form of mercury(II) $N, N$ diisopropyldithiocarbamate. Chem. Lett. 1978, 7, 1399-1402.

50. Loseva, O. V.; Rodina, T. A.; Smolentsev, A. I.; Ivanov, A. V., A new polymorphic modification and chemisorption activity of mercury(II) N,N-di-iso-propyldithiocarbamate: Synthesis and characterisation of the heteronuclear double complex of ([Au $\left\{\mathrm{S}_{2} \mathrm{CN}\right.$ (iso$\left.\left.\left.\left.\mathrm{C}_{3} \mathrm{H}_{7}\right)_{2}\right\}_{2}\right]_{2}\left[\mathrm{Hg}_{2} \mathrm{Cl}_{6}\right] \cdot \mathrm{OC}\left(\mathrm{CH}_{3}\right)_{2}\right)_{\mathrm{n}}$. Polyhedron 2017, 134, 238-245.

51. Healy, P. C.; Connor, J. W.; Skelton, B. W.; White, A. H., Alkyl Substituent Effects in Diamagnetic Dithiocarbamate Cobalt and Nickel Complexes. Aust. J. Chem. 1990, 43, 10831095.

52. J. Ma, F. B., J. Li, X. Yang, L. Lu, X. Wang, Solid Phase Synthesis at Room

Temperature, Characterization and Crystal Structure of bis(diiso-propylcarbamodithioato-S,S') Molybdenum. J. Nanjing University of Science and Technology 2004, 28, 648-652.

53. Newman, P. W. G.; White, A. H., Crystal Structure of Bis(NN-diisopropyldithiocarbamato)nickel( 11). J.C.S Dalton 1972, 2239-2243.

54. Iwasaki, H.; Kobayashi, K., Structure of bis(N,N-diisopropyldithiocarbamato)copper(II). Acta Crystallograph. Sect. B 1980, 36, 1655-1657.

55. Xu, L.-Z.; Zhao, P.-S.; Zhang, S.-S., Crystal Structure and Characterization of Pd(II) Bis(diiso-propyldithiocarbamate) Complex. Chin. J. Chem. 2001, 19, 436-440.

56. Tables of interatomic distances and configuration in molecules and ions. The Chemical Society: London, 1958.

57. Ivanov, A. V.; Korneeva, E. V.; Bukvetskii, B. V.; Goryan, A. S.; Antzutkin, O. N.; Forsling, W., Structural organization of mercury(II) and copper(II) dithiocarbamates from EPR and $13 \mathrm{C}$ and $15 \mathrm{~N}$ MAS NMR spectra and X-ray diffraction analysis. Russ. J. Coord. Chem. 2008, 34, 59-69.

58. Harris, R. K.; Jonsen, P.; Packer, K. J., Residual (13C, 14N) dipolar coupling in 13C NMR of solid nitrogen-containing aromatic compounds. Magn. Reson. Chem. 1985, 23, 565-577. 59. Wi, S.; Frydman, L.; J., S.; O., S. E., Residual dipolar couplings between quadrupolar nuclei in high resolution solid state NMR: Description and observations in the high-field limit. $J$. Chem. Phys. 2000, 112, 3248-3261.

60. Olivieri, A. C.; Frydman, L.; Grasselli, M.; Diaz, L. E., Microcomputer simulation of solid-state ${ }^{13} \mathrm{C}$ NMR line shapes affected by quadrupolar nuclei. Magn. Reson. Chem. 1988, 26, 615.

61. Bowmaker, G. A.; Churakov, A. V.; Harris, R. K.; Howard, J. A. K.; Apperley, D. C., Solid-State ${ }^{199} \mathrm{Hg}$ MAS NMR Studies of Mercury(II) Thiocyanate Complexes and Related Compounds. Crystal Structure of $\mathrm{Hg}(\mathrm{SeCN})_{2}$. Inorg. Chem. 1998, 37, 1734-1743.

62. Natan, M. J.; Millikan, C. F.; Wright, J. G.; O'Halloran, T. V., Solid-state mercury-199 nuclear magnetic resonance as a probe of coordination number and geometry in $\mathrm{Hg}$ (II) complexes. J. Am. Chem. Soc. 1990, 112, 3255-3257.

63. Leckey, J. H.; Nulf, L. E. Thermal decomposition of mercuric sulfide; Y/DZ-1124; Oak Ridge Y-12 Plant, TN (United States): 1994.

64. Loseva, O. V.; Rodina, T. A.; Smolentsev, A. I.; Ivanov, A. V., Syntheses, supramolecular structures, and thermal behavior of heteronuclear gold(III)-mercury(II) 
dithiocarbamatochloride complexes $\left[\mathrm{Au}\left\{\mathrm{S}_{2} \mathrm{CN}\left(\mathrm{CH}_{3}\right)_{2}\right\}_{2}\right]_{2}\left[\mathrm{HgCl}_{4}\right]$ and $\left(\left[\mathrm{Au}\left\{\mathrm{S}_{2} \mathrm{CN}\left(\mathrm{C}_{2} \mathrm{H}_{5}\right)_{2}\right\}_{2}\right]_{2}\left[\mathrm{Hg}_{2} \mathrm{Cl}_{6}\right] \cdot \mathrm{OC}\left(\mathrm{CH}_{3}\right)_{2}\right)$ n by ${ }^{13} \mathrm{C}$ MAS NMR, X-ray diffraction, and simultaneous thermal analysis data. Russ. J. Coord. Chem. 2016, 42, 719-729.

65. Harris, K. J.; Lupulescu, A.; Lucier, B. E. G.; Frydman, L.; Schurko, R. W., Broadband adiabatic inversion pulses for cross polarization in wideline solid-state NMR spectroscopy. $J$. Magn. Reson. 2012, 224, 38-47.

66. MacGregor, A. W.; O’Dell, L. A.; Schurko, R. W., New methods for the acquisition of ultra-wideline solid-state NMR spectra of spin-1/2 nuclides. J. Magn. Reson. 2011, 208, 103 113.

67. Eichele, K. WSolids1, 1.21.3; Universität Tübingen, 2015.

68. Sheldrick, G. M., A Short History of SHELX. Acta Crystallograph. Sect. A 2008, 64, 112-122.

69. Dolomanov, O. V.; Bourhis, L. J.; Gildea, R. J.; Howard, J. A. K.; Puschmann, H., OLEX2: a complete structure solution, refinement and analysis program. J. Appl. Crystallogr. 2009, 42, 339-341. 


\section{For Table of Contents Use Only}

\section{An unusual mercury(II) di-isopropyldithiocarbamate coordination polymer}

Alexander Angeloski, Aditya Rawal, Mohan Bhadbhade, James M. Hook, Robert W. Schurko and Andrew M. McDonagh

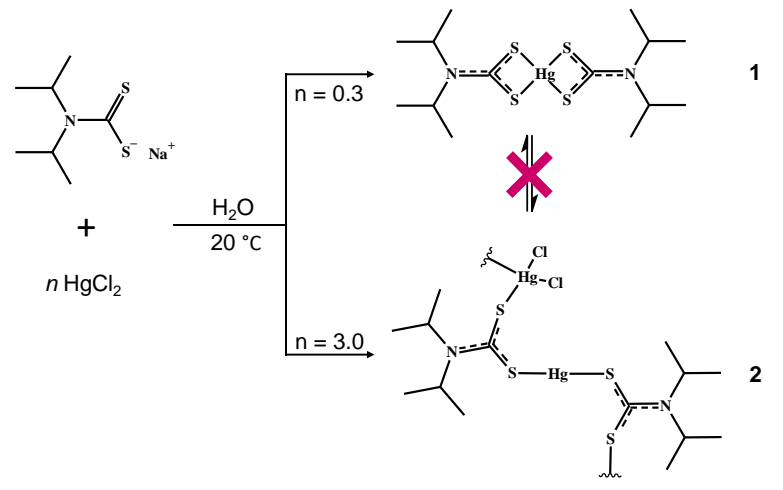

A new polymeric mercury(II) di-isopropyldithiocarbamate complex was synthesized by the reaction of sodium di-isopropyldithiocarbamate with excess $\mathrm{HgCl}_{2}$ in water. A similar reaction using a stoichiometric excess of the ligand yielded the monomeric bis(di(isopropyl)dithiocarbamato)mercury(II) complex. Solid state NMR spectroscopy $\left({ }^{199} \mathrm{Hg}\right.$ and ${ }^{13} \mathrm{C}$ ) provided unambiguous data and showed that the monomeric complex and polymeric complex do not interconvert in solution or during crystal growth. 